show that: (1) all are characterized by large concentrations of $i$ lmenite (IIm $>>G t>>P X)$ with Mali>Liberia>Guinea>Sierra Leone; (2) Antoschka (Guinea) exhibits the largest variety of opaque minerals (Ilm+Rut+Sp); (3) Mali is characterized by low $\mathrm{T}$ anatase+Hem replacement of $\mathrm{I} 1 \mathrm{~m}$, and Sierra Leone has abundant sulfides (Cpy+Po+Pn) within $11 \mathrm{~m}$; (4) extremely large (10-15 cms) I1m are derived from Liberia; (5) Sierra Leone and isolated sites in Liberia have high MnO (16wt\% max) contents in $11 \mathrm{~m}$ associated with calcite; (6) large variations and considerable overlap exist within and between kimberlite clusters in Ilm-Geik-Hem contents; (7) subsolidus reduction of $\mathrm{I} 1 \mathrm{~m}$ to $2 \mathrm{Ilm}_{\mathrm{SS}}+\mathrm{Sp}_{\mathrm{SS}}$ is unique to Sierra Leone whereas exsolution of $11 m_{S s}$ from $I 1 m-G e i k-i \cdot e m_{S S}$ are restricted to Liberia and Antoschka; (8) $\mathrm{Cr}_{2} \mathrm{O}_{3}-\mathrm{MgO}$ variations are either tightly clustered along a parabolic curve delineated by $\mathrm{Mg}_{\mathrm{I}} \mathrm{Mg}_{\mathrm{sp}}$ or dispersed within a broad hyperbolic envelope; (9) a coherent pattern of compositional variations is established between $I 1 \mathrm{~m}-\mathrm{I} 1 \mathrm{~m}_{\mathrm{ss}}$ pairs which define a decompositional loop in the ternary IIm-Geik-Hem that is consistent with experimental data at variable $\mathrm{T}-\mathrm{fO}_{2}$; and (10) by using the data from (9) and combined with I $1 \mathrm{~m}$ compositions from southern Africa it is concluded that the dominant control on $11 \mathrm{~m}$ compositions is the $\mathrm{T}-\mathrm{fO}_{2}$ dependency of immiscibility within the system I1m-Geik-Hem, such that I1m$\mathrm{Hem}_{\mathrm{Ss}}$ and Ilm-Geikss are permissible, Geik$\mathrm{H}_{\mathrm{S}}$ are absent, and intermediate (I Im-Hem)(Geik-Hem) $)_{\mathrm{ss}}$ are restrictive because $\mathrm{Sp}_{\mathrm{ss}}+(\mathrm{Pb}+$ $\mathrm{Kar}+\mathrm{FPb})_{\mathrm{Ss}}$ is stable at low P.

\section{D27}

COMPLEX TITANATE COMPOUNDS $\left(\mathrm{MO}_{2}, \mathrm{M}_{2} \mathrm{O}_{3}, \mathrm{M}_{3}\right.$ $\mathrm{O}_{5}, \mathrm{M}_{4} \mathrm{O}_{7}, \mathrm{M}_{22} \mathrm{O}_{38}$ ) IN KIMBERLITES : MINERAL REP. OSITORIES FOR AND THE PARTITIONING OF LIL

\section{ELEMENTS.}

STEPHEN E. HAGGERTY

Dept. of Geology, University of Massachusetts, Amherst, MA 01003, USA

The mineralogy and genesis of components hosting large concentrations of (R) refractory (e.g., $\mathrm{Cr}, \mathrm{Nb}, \mathrm{Ta}, \mathrm{Zr}$ ) and LIL (e.g., K, Ba, Sr, REE) elements in kimberlites and kimberlite nodules provide insights to the nature of mantle reservoirs, may be used to impose constraints on degrees of partial melting, and may yield independent estimates of originating depths and sites of equilibration. $R$ and $L I L$ are abundant in rutile $\left(\mathrm{MO}_{2}\right)$, perovskite $\left(\mathrm{M}_{2} \mathrm{O}_{3}\right)$, armalcoliterelated $\left(\mathrm{M}_{3} \mathrm{O}_{5}\right)$, zirconolite $\left(\mathrm{M}_{4} \mathrm{O}_{7}\right)$, and crichtonite-related $\left(\mathrm{M}_{22} \mathrm{O}_{38}\right)$ minerals. However, with the exception of $\mathrm{MO}_{2}\left(\mathrm{TiO}_{2} \mathrm{II}\right)$ none of these compounds have established high $P$ stabilities. It is proposed that substitution of $\mathrm{Cr}, \mathrm{Zr}$, and $\mathrm{Nb}$ into $\mathrm{TiO}_{2}$ may be accomplished in compounds related to the high $\mathrm{P}$ parent structure $\propto \mathrm{PbO}_{2}$ by crystallographic shear (CS) comparable to those in the series $M_{n} O_{2 n-1}-M_{n} O_{3 n-2}(n=1, ?, 3)$ and to $\mathrm{Cr}_{2} \mathrm{Ti}_{n-2} \mathrm{O}_{2 n-1}(\mathrm{n}=3,4,5)$. Such compounds, on ascent-equilibration, yield a viable explanation for the occurrence of $\mathrm{M}_{3} \mathrm{O}_{5}$ (armalcolite type) in association with rutile and ilmenite, and for the ubiquitous presence of rutile and ilmenite intergrowths. $\mathrm{Ba}-\mathrm{K}(\mathrm{Sr}, \mathrm{Pb}, \mathrm{Ca}, \mathrm{REE})$ members of $\mathrm{M}_{22} \mathrm{O}_{38}$ compounds decompose to rutiletspinel+X....n phases suggestive of site occupation of LIL at high P into phases other than CS based structures. Using the model precursors of CS and non-CS structured compounds ( $\mathrm{i} . \mathrm{e} ., \propto \mathrm{PbO}_{2}$ and $\mathrm{M}_{22} \mathrm{O}_{33}$ ) and constrasts in paragenesis, two distinct $\mathrm{R}+$ LIL evolutionary trends emerge: (a) in which $\mathrm{Nb}+\mathrm{Zr}+\mathrm{C} r+\mathrm{K}$ are complexed as high $\mathrm{P}$ incompatible liquid residua into $\mathrm{MO}_{2}, \mathrm{M}_{4} \mathrm{O}_{7}\left(\mathrm{Cr}_{2} \mathrm{Ti}_{2} \mathrm{O}_{7}\right)$ or $\mathrm{M}_{22} \mathrm{O}_{38}$ type compounds in rodules; and (b) low $\mathrm{P}$ melt residua in which $T i$ fractionates to form R-depleted ilmenite and a Ti+REE sink in perovskite at the terminal stages of kimberlite crystallization.

\section{D28}

A LAYERED DUNITE - WEHRLITE - WEBSTERITE FROM NEWLANDS, SOUTH AFRICA; EVIDENCE FOR SMALL SCALE FRACTIONAL CRYSTALLIZATION IN THE MANTLE.

\section{L.R.M. DANIELS}

Falconbridge Explorations (Botswana) (Pty) Limited, P.O. Box 1463 Gaborone.

A layered mantle xenolith, LDN-10, has been found in the Newlands kimberlite. The bulk composition, calculated from modal mineral proportions, approximates a peridotitjc Komatiite. The following layers are recognised: a) Dunite b) Wehrlite c) Gt-Wehrlite d) Gt-hebsterite. Olivine and orthopyroxenes show minor ehemical variations across the xenolith. The garnets and clinopyroxenes are strongly zoned, particularly with respect to $\mathrm{Cr}_{2} \mathrm{O}_{3}$, which also decreases systematically from the wehrlitie layers to the websteritic layer.

The layering in $1 . \mathrm{DN}-10$ can be interpreted in terms of a fractio:al crystallisation model that is consistent with phase relations estab] ished for the CMAS tetrahedron (0'llara, 1968). In this mode?, with a liquid corresponsing to the bulk eomposition for I.DN-10, the first mineral phase to crystallise will be olivine, followed by clinopyroxene, garnet and orthopyroxene resneetively. This crystallisation sequence is reflected by the observed minerai as:semblages in LD:i-10 and is eonsistent with the observed $\mathrm{Cr}_{2} \mathrm{O}$ s variation of both elinopyroxene and garnet.

Gurney et al (1075) proposcd a fractional crystallisation model for the Matsolu xenolith suite. It is suggested that inv-10 represents a similar tipe of mantle process, but on mueh smailer scale.

References:

Gurney J.J., Harte B., and Cox K.G. 1975: Phys. Chem. Farth 9, 507-523.

O'Hara M.J.,1968: Earth Sei.Rev. 4, 69-133.

\title{
(Late abstract) \\ MANTLE MINERAL ASSEMBLAGES AND PALAEOGEOTHERMS
}

\section{A. B. THOMPSON and S.L. HARLEY}

(ETH Zurich, $\mathrm{CH}-8092$ Zurich, Switzerland)

Many recent studies of the quenched mineral assemblages in magmas considered to have a deep mantle origin (alkali basalts and kimberlites) and their enclosed nodules, have sought to determine the depth at which the mineral geothermome- ters closed to further reequilibration. If the deduced P-T-points lie on a curve, then they are frequently interpreted to define the P-T-location of a palaeogeotherm. If the deduced P-T-points form an array, then uncertainties in P-T-calibra- 
tion of a simplified chemical system (or the inherent problems in extrapolating from simple to complex crystalline solutions) are introduced to accommodate a desired palaeogeotherm. The hypothetical "Kinked or perturbed" palaeogeotherms have been straightened by some authors on grounds of mineralogical problematics. Likewise, more recent studies have shown that the deduced $\mathrm{P}-\mathrm{T}-$ equilibration conditions for sheared or unsheared nodules are only mutually exclusive. Even if we take the generous and pragmatic viewpoint that deduced $\mathrm{P}-\mathrm{T}$-points from quenched magmas and their nodules do not reflect reequilibration en-route to the surface, we are still faced with the prob- lem of what the nodules represent with reference to the enclosing magma and whether the $\mathrm{P}-\mathrm{T}-\mathrm{cond}-$ itions are anomalous in the long-term evolution of the mantle.

We have attempted to use trace element and other geochemical indicators together with constraint on mantle metamorphism and melting in a framework governed by time-dependent convective instability in the mantlè, to consider, among other characteristics, the age clustering of kimberlites (or their nodules, their location in crustal fracture zones and the distinctly different depths of alkali basalt versus kimberlite magma genesis.

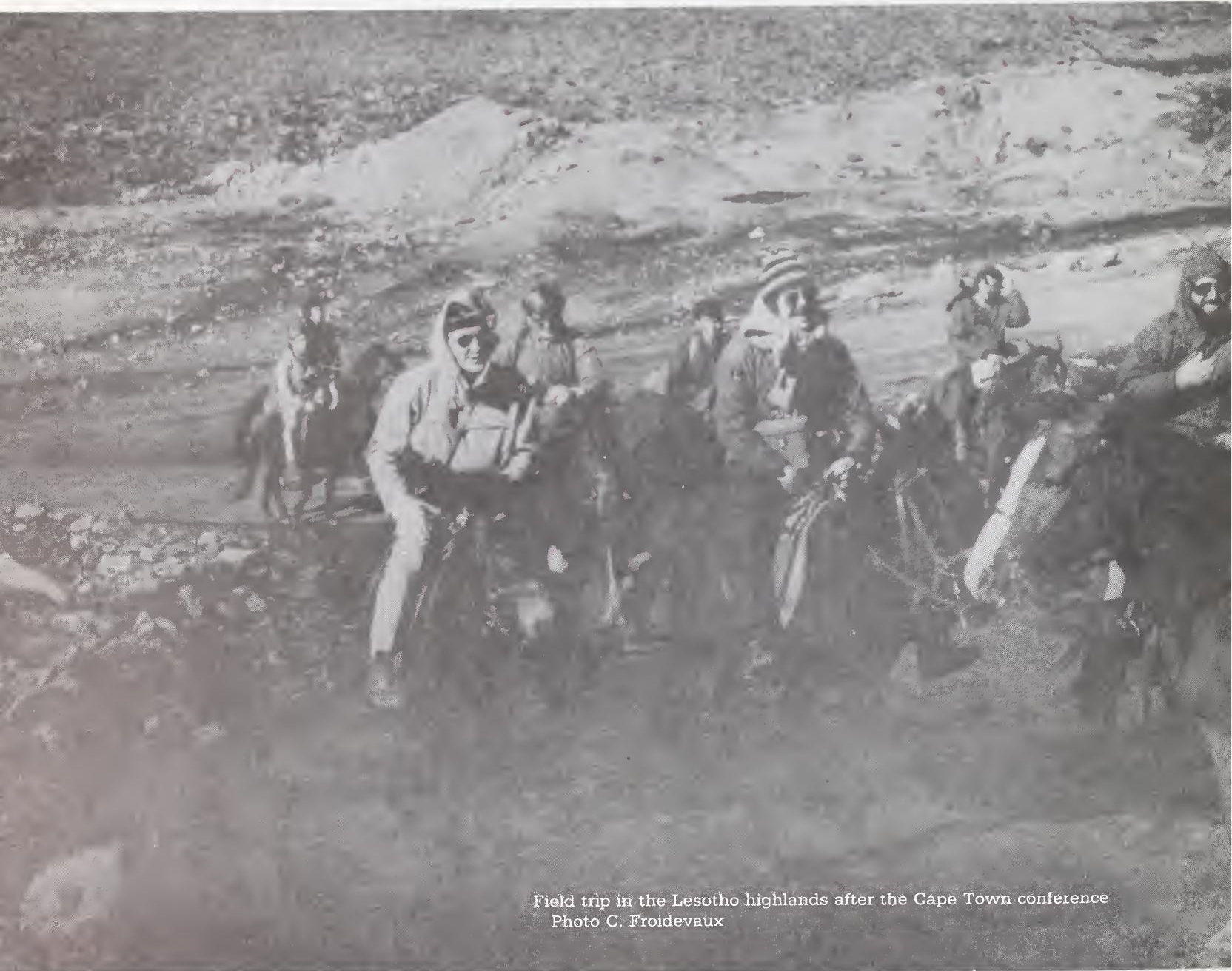

